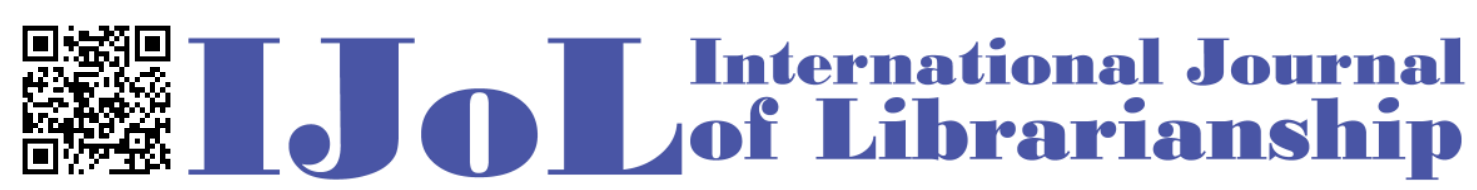

ISSN: 2474-3542 Journal homepage: http://journal.calaijol.org

\title{
Development of a Web-Based GIS Learning Module for Community Asset Mapping to Enhance Service Learning in Social Work Education
}

Xue Luo and Wansoo Park

\begin{abstract}
:
In recent years, service learning - a pedagogical approach that integrates learning through service in the community - has gained increasing popularity in higher education as a means to enhance student learning and civic engagement. Service learning is relevant to social work education because of its emphasis on social justice and the amelioration of social problems and field education through practicum sites. The benefits of service learning, however, are dependent on successful integration of this pedagogical approach into the classroom. By developing a web-based learning module, this project aims to explore the possibility of using community asset mapping and geographic information systems (GIS) as an integrated technology tool to promote service learning in social work education. An assessment of this module was conducted by a student survey. The overall positive feedback on the module indicates its contribution to social work study as well as its potential applicability to larger contexts. The project can serve as a starting point for developing best practices for the training of students in mapping and spatial thinking in their community practices that would benefit other disciplines as well. The project supports the university's mission to improve student-centred, interdisciplinary, and innovative teaching and learning, and its commitment to enhance the economic and social well-being of the local communities.
\end{abstract}

To cite this article:

Luo, X., \& Park, W. (2020). Development of a Web-Based GIS Learning Module for Community Asset Mapping to Enhance Service Learning in Social Work Education.

International Journal of Librarianship, 5(1), 36-52.

https://doi.org/10.23974/ijol.2020.vol5.1.159

To submit your article to this journal:

Go to https://ojs.calaijol.org/index.php/ijol/about/submissions 


\title{
Development of a Web-Based GIS Learning Module for Community Asset Mapping to Enhance Service Learning in Social Work Education
}

\author{
Xue Luo and Wansoo Park \\ University of Windsor, Windsor, Ontario, Canada
}

\begin{abstract}
In recent years, service learning - a pedagogical approach that integrates learning through service in the community - has gained increasing popularity in higher education as a means to enhance student learning and civic engagement. Service learning is relevant to social work education because of its emphasis on social justice and the amelioration of social problems and field education through practicum sites. The benefits of service learning, however, are dependent on successful integration of this pedagogical approach into the classroom. By developing a web-based learning module, this project aims to explore the possibility of using community asset mapping and geographic information systems (GIS) as an integrated technology tool to promote service learning in social work education. An assessment of this module was conducted by a student survey. The overall positive feedback on the module indicates its contribution to social work study as well as its potential applicability to larger contexts. The project can serve as a starting point for developing best practices for the training of students in mapping and spatial thinking in their community practices that would benefit other disciplines as well. The project supports the university's mission to improve student-centred, interdisciplinary, and innovative teaching and learning, and its commitment to enhance the economic and social well-being of the local communities.
\end{abstract}

Keywords: Service Learning, GIS, University Community Collaboration for Teaching, Higher Education.

\section{INTRODUCTION}

In recent years, service learning, a pedagogical approach that integrates learning through service in the community, has gained increasing popularity in higher education as a means to enhance student learning and civic engagement. The benefits of service learning, however, are dependent on successful integration of this pedagogical approach into the classroom. Some have suggested adopting an asset-based approach, community asset mapping, as an effective means of preparing students for service learning (Garoutte \& McCarthy-Gilmore, 2014). As a digital method of mapping, geographic information systems (GIS) provides a flexible and sophisticated way to display community assets. 
Located in the southernmost city in Canada, the University of Windsor is a comprehensive, student-focused university with nearly 16,000 students enrolled in a broad range of undergraduate and graduate programs. One of the University of Windsor's strategic priorities is to "engage the community in partnerships that strengthen the economic and social well-being of the WindsorEssex region" (University of Windsor, 2010). The academic response among faculty has been to incorporate service learning into class content across a wide array of disciplines. In particular, the School of Social Work has introduced community asset mapping in some courses as a tool for engaging students in community service activities in order to prepare them for future professional practice. However, the mapping process itself can be quite challenging for many students due to a lack of appropriate GIS skills and accessible training. Although other departments have offered GIS courses, they tend to be focused on natural science areas and are designed for professionals in earth science or engineering. Consequently, developing GIS training tailored to the specific needs of social work students was both timely and relevant to current needs in this institution.

The Leddy Library is the main campus library for the University of Windsor. It has been recognized as a valued partner on campus to enhance student experience and support university research and academic initiatives. Traditionally, the Geospatial and Data Analyst from Leddy Library gave a lecture to individual classes on the basics of GIS and its potential application in the social work profession. It is usually a single, abbreviated session (one to two hours) without software demonstrations or hands-on activities. However, information technology skills, such as GIS, take time to develop and practice. Without hands-on experience with GIS software, students cannot fully obtain the necessary skills to apply GIS in the asset mapping process. In addition, there is a recognition that GIS is most effectively taught in the context of practical applications (Wier \& Robertson, 1998). Therefore, using community asset mapping as the core learning activities can provide students with a meaningful context for learning and using GIS.

Given the increasing demand for GIS skills in higher education and the lack of appropriate training opportunities in social work education, this project had two objectives: (1) to develop an online learning module to teach social work students how to use GIS tools to create community asset maps, and (2) to test the effectiveness of the combination of online learning module, off-line lecture, and course assignment on students learning in two graduate level courses. Research indicates that varied modes of delivery influence student skill development (Maclachlan, et al., 2014) and a combination of online tutorials with in-class instruction is the most beneficial method for teaching GIS to students by accommodating their different learning styles (Wier and Robertson, 1998). Learning objectives of the GIS module were: students will be able to develop a clear understanding of what GIS is and how it can be used in asset mapping to enhance community practice; they will be able to identify assets within a community, gather relevant data and transfer them into a GIS compatible format to create asset maps suitable for publishing and sharing; and they will be able to interpret and communicate the results to the community.

\section{LITERATURE REVIEW}

In response to rapid changes in society and the labour market, many universities and colleges have introduced more experiential learning opportunities, such as community service learning, to enhance student civic engagement and improve post-graduation outcomes (Taylor et al., 2015). Service learning is a pedagogical approach that engages students in activities that address actual 
community needs together with formal course-based learning activities intentionally designed to promote student learning and development (Gerstenblatt \& Gilbert, 2014; Jacoby, 2009; Taylor et al., 2015). With their emphasis on service, empowerment, and traditional use of field practicums, social work programs have been viewed as natural hosts for the use of service learning pedagogy (Phillips, 2011) and the compatibility of service learning and social work education has led to increased use of service learning in a wide range of social work courses (Gerstenblatt \& Gilbert, 2014; McGuire \& Majewski, 2011).

A strength of service learning is that it places equal emphasis on three outcomes: student learning, service to the community, and the development of reciprocal relationships between students and community partners (Harkavy, 2004; Lemieux \& Allen, 2007). However, the implementation of service learning sometimes falls short of these goals mainly due to the way service-learning activities are designed. For example, since traditional service-learning models typically focus on what needs to be fixed or what is lacking within a community, students are likely to position themselves as persons giving services for those in need (Bauer, Kniffin \& Priest, 2015). Such an interpretation of service learning may perpetuate privilege and reinforce structures of hierarchy and power (Garoutte \& McCarthy-Gilmore, 2014). In order to address this issue, some researchers have suggested adopting an asset-based approach, community asset mapping, as an effective means of creating authentic university-community partnerships while promoting student community engagement (Garoutte \& McCarthy-Gilmore, 2014). Community asset mapping encourages one to focus on a community's assets and strengths rather than its needs and deficiencies (Kretzmann \& McKnight, 1993). A community asset is anything that can be used to improve the quality of community life (Centre for Community Health and Development, 2020). Community assets can include skills, knowledge, and experience of community members; the organizations and institutions that provide services for the community, (e.g., schools, libraries, hospitals, recreation centres); businesses that provide jobs and support the local economy; a physical structure or place, (e.g., town squares, heritage buildings); natural resources, (e.g., rivers, trees, green spaces). The asset mapping process typically involves a series of steps including identifying community assets through neighbourhood canvassing, building a community profile and visual map of the community, and developing and implementing an action plan (Garoutte \& McCarthy-Gilmore, 2014). In this way, community asset mapping encourages students to do things "with" community members rather than "for" them, thus allowing them to engage reciprocally with their community without participating in hierarchical or one-way university-community relationships.

Essential to the asset mapping process is the creation of a map that visually represents the community's assets. In the past, one needed to find an existing street map or physical map and mark the geographic location of various types of resources, which was very arduous and slow. More recently, the use of GIS is emerging as a more flexible and sophisticated way to display community assets than paper-and-pushpin mapping. Within GIS, different types of information, for example, locations of health care facilities, street networks, school board boundaries, and population density, are represented as individual map layers, which can be overlaid on top of one another. By identifying where assets are in relationship to each other, GIS enables students to address a variety of questions that otherwise might be very time-consuming or too difficult to resolve. Some examples include identifying where community assets are concentrated versus where they are sparse, examining where community resources are located in relation to where people live, and exploring the relationships among various types of assets as well as the 
relationships between specific features and community attributes (Sharpe, Greaney, Lee, \& Royce, 2000). An increasing number of higher education institutions have implemented asset mapping within their service learning programs and have shown promising results (Bauer, Kniffin \& Priest, 2015; Donaldson and Daughtery, 2011; Garoutte and McCarthy-Gilmore, 2014). There is growing interest in using GIS in social work research and practice (Felke, 2014, 2019; Hillier, 2007; Wier \& Robertson, 1998). However, with a few exceptions, GIS has not found its way into the social work curriculum (Felke, 2014, 2019; Hillier, 2007). Therefore, the current study aimed to explore how GIS and asset mapping can be employed as integral tools for service learning to promote community awareness and engagement among students.

\section{METHODOLOGY}

\section{Online Module Development}

The GIS module was developed in the summer of 2017. The development of the module was coordinated within the Leddy Library's Academic Data Centre. It was developed by the Geospatial and Data Analyst with consultation from the course instructor from the School of Social Work. The module was tested and adapted to the university Blackboard online learning management system through the help of a research assistant. The aim of this module was to introduce students to the basic principles of GIS and provide them with the necessary skills to collect, edit, and display spatial data on community assets by using open source GIS software and free web resources. The module was composed of basic introductory materials, concrete task-based tutorials, and example datasets. The approximate time to complete the module was 4-6 hours.

\section{Lecture in Graduate Courses and Assignment}

In the fall of 2017 and the winter of 2018, the module was piloted in two graduate-level social work courses: community practice course in the foundation year of the two-year Master of Social Work program and the program evaluation course in the advanced year of the program. The online module was available to students anywhere and at any time, and was complemented by face-toface instruction. A community asset mapping assignment was developed as part of the course assignments. Student groups were expected to produce a map, present it to the class, and communicate it to the public.

\section{Student Survey}

In order to assess students' learning experience and learning outcome before and after using the module, a structured survey questionnaire was administered in paper and pencil format to all students attending the last class of the two courses. The retrospective pretest design was chosen in this study because growing evidence has shown that this approach can help reduce the responseshift bias that frequently occurs in the traditional pre-post test design by clearing up misconceptions before participants are asked to make assessments (Lamb, 2005). At the end of the semester, a short, five-minute in-class presentation was given to introduce the survey by the research assistant. Then, each student received a survey package including a letter of information/consent and the questionnaire. The survey included questions related to demographics, prior experiences with GIS, use of the module, experiences using the module, and perceptions of 
module contribution to student learning within and beyond the course. Survey participation was voluntary, and students were given 30-40 minutes to complete it. After the questionnaire was completed, four students were randomly selected to receive \$25 Amazon gift cards. The University Research Ethics Board clearance was obtained for this project (REB \#34206).

\section{RESULTS}

\section{Demographic Profile of Students Survey Respondents}

The student survey results were analyzed using the Statistical Package for the Social Sciences (SPSS 23). A total of 53 out of 87 students enrolled in the above two courses responded to the survey, a response rate of $61 \%$. The respondents were largely females $(88 \%)$ in the $20-24$ age group (51\%). They were either enrolled in the first (33.3\%) or second year $(66.7 \%)$ of the Master of Social Work program. Only a small percentage of respondents reported that they had experience with mapping or attended a GIS tutorial session before the course (Figure 1). Among those who had GIS training, most of them received such training in social work classes at University of Windsor in the last two years (Table 1).

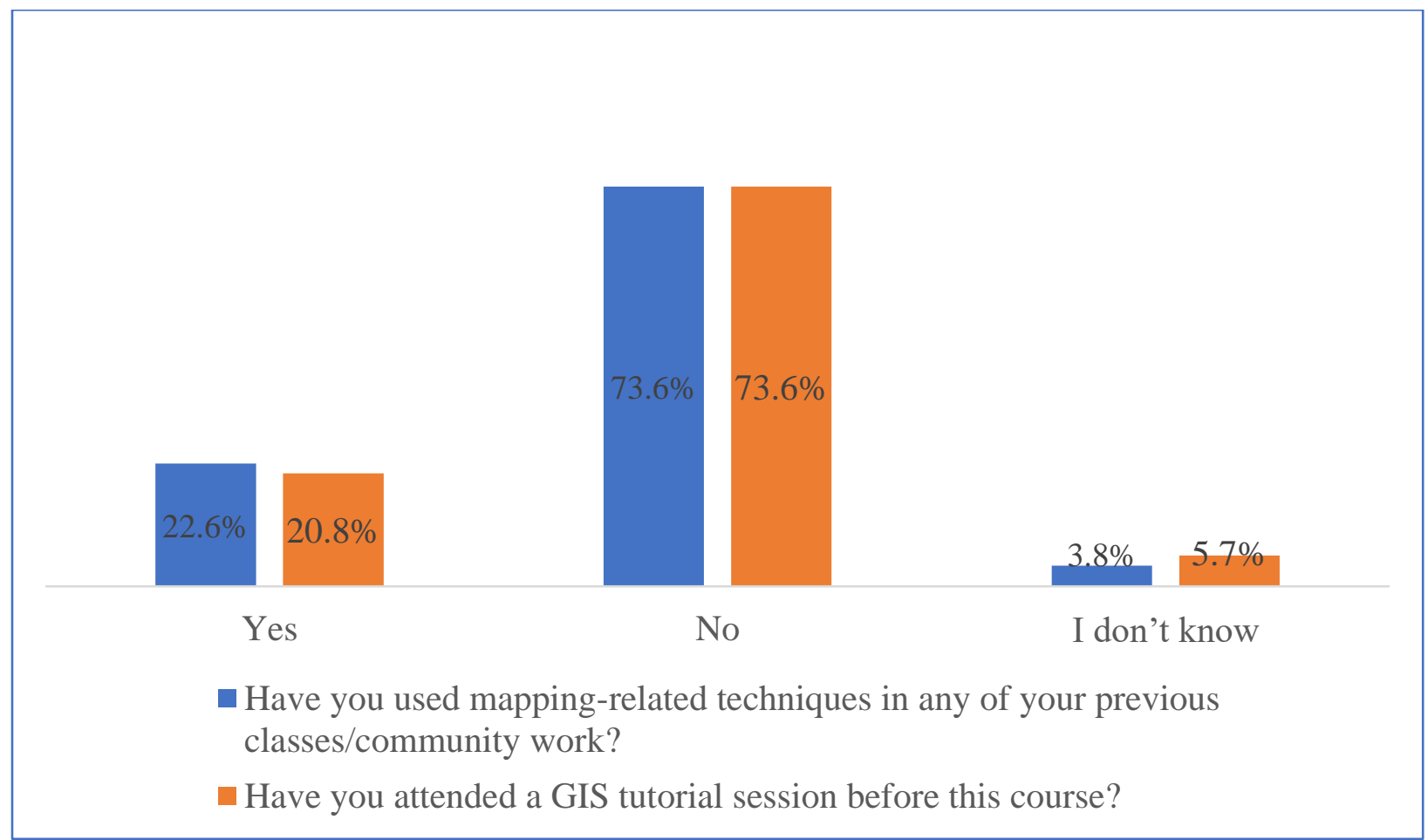

Figure 1. Student prior experience with GIS 
Table 1. "Where" and "when" of previous GIS training if students had one before the course

\begin{tabular}{|llr|}
\hline & Response & \% of Responses $(\mathbf{n}=\mathbf{5 3})$ \\
\hline Where & In social work classes at University of Windsor & $92.3 \%$ \\
\hline Online & $7.7 \%$ \\
\hline & Less than 1 year ago & $30.8 \%$ \\
\hline & 1 to 2 years ago & $53.8 \%$ \\
\hline & 3 to 4 years ago & $7.7 \%$ \\
\hline
\end{tabular}

\section{Student Use of Modules}

In order to encourage students to use the module, one of the assignments in each course was to create an online GIS map and answer a set of questions based on it. Due to the different nature of the contents of each course, as well as the depth of GIS usage built into each course, student responses to the remaining questions of the survey were analyzed separately by course. The result indicates that less than half $(47 \%)$ of student respondents in the program evaluation course reported revisiting the module again after initial use, while $68.5 \%$ of the community practice course respondents indicated that they had referred back to the modules at least one additional time. This difference could be due to the different weighting and nature of the GIS-related assignment between the two courses. In the community practice course, the GIS map and community assessment presentation was weighted $30 \%$ of the course grade, while in the program evaluation course, the GIS map assignment was only $12 \%$ and it was done as part of the in-class assignment. When asked about why they used the module (Table 2), while the majority of respondents in both courses reported they did so because it earned them marks, a significant portion of students also reported that they felt the module helped them understand the course material. This finding clearly supports the idea of adopting the module as a course assignment with marks attached instead of doing it as a simple classroom activity to increase student usage. However, only a small portion of students reported that they use the module because it helped them understand the material in other courses or it allowed them to work at their own pace. 
Table 2. The "why" of student module use. Students could choose more than one applicable answer for each question.

\begin{tabular}{|c|c|c|c|}
\hline & & $\begin{array}{l}\text { Community } \\
\text { Practice } \\
\text { Course } \\
\end{array}$ & $\begin{array}{l}\text { Program } \\
\text { Evaluation } \\
\text { Course } \\
\end{array}$ \\
\hline Question & Response & $\begin{array}{c}\% \text { of } \\
\text { Responses } \\
(\mathrm{n}=19)\end{array}$ & $\begin{array}{c}\% \text { of } \\
\text { Responses } \\
(\mathrm{n}=34)\end{array}$ \\
\hline \multirow{4}{*}{$\begin{array}{l}\text { Why did you use the GIS } \\
\text { module in your course? }\end{array}$} & $\begin{array}{l}\text { Because it helped me } \\
\text { understand the course material }\end{array}$ & $57.9 \%$ & $41.2 \%$ \\
\hline & $\begin{array}{l}\text { Because it helped me } \\
\text { understand the material in other } \\
\text { courses }\end{array}$ & $15.8 \%$ & $29.4 \%$ \\
\hline & $\begin{array}{l}\text { Because it allowed me to work } \\
\text { at my own pace }\end{array}$ & $10.5 \%$ & $8.8 \%$ \\
\hline & Because it earned me marks & $78.9 \%$ & $67.6 \%$ \\
\hline
\end{tabular}

\section{Assessment of Modules}

The following questions of the survey were used to understand the potential impact of the GIS module on student learning experience and learning outcome. First, we asked students about their satisfaction with the presentation and organization of the module. As shown in Figure 2, the students' responses in the two courses were generally similar. The majority of respondents in both courses felt that the module was straightforward and easy to navigate and was delivered in a way that allows for a logical and manageable learning pace. However, less than half of students in both courses felt that the module made them take more responsibility for their own learning. This finding needs to be considered in future development of the module. Although more than half of students in the community practice course felt that the module suited their learning style and they would like to have such experience again in the future, less than half of students in the program evaluation course did so. One possible explanation could be that students in the community course were in the first year and it would be most likely their first time learning about how to use GIS, while students in the program evaluation course are graduating and they might have had more opportunities to learn about GIS over the previous years. 


\section{Community Practice Course}

Overall, the mode of delivery for the GIS module was an experience I want to have again.

The GIS module made me take more responsibility for my own learning.

The GIS module suited my learning style.

The GIS module offered a logical and manageable learning pace.

The GIS module delivered information in a straightforward manner.

The GIS Module was easy to navigate

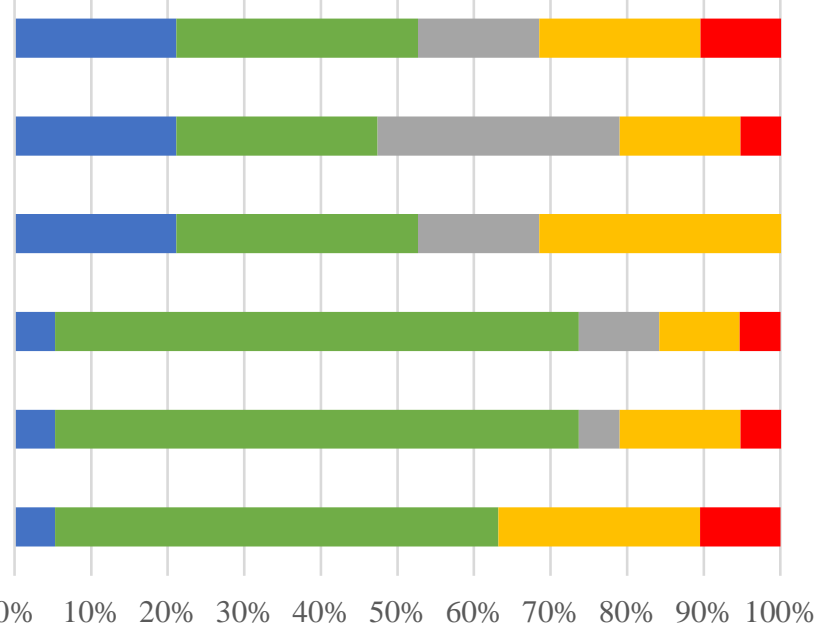

- Strongly Agree $\square$ Agree $\square$ Neutral $\square$ Disagree $\square$ Strongly Disagree

\section{Program Evaluation Course}

Overall, the mode of delivery for the GIS module was an experience I want to have again.

The GIS module made me take more responsibility for my own learning.

The GIS module suited my learning style.

The GIS module offered a logical and manageable learning pace.

The GIS module delivered information in a straightforward manner.

The GIS Module was easy to navigate
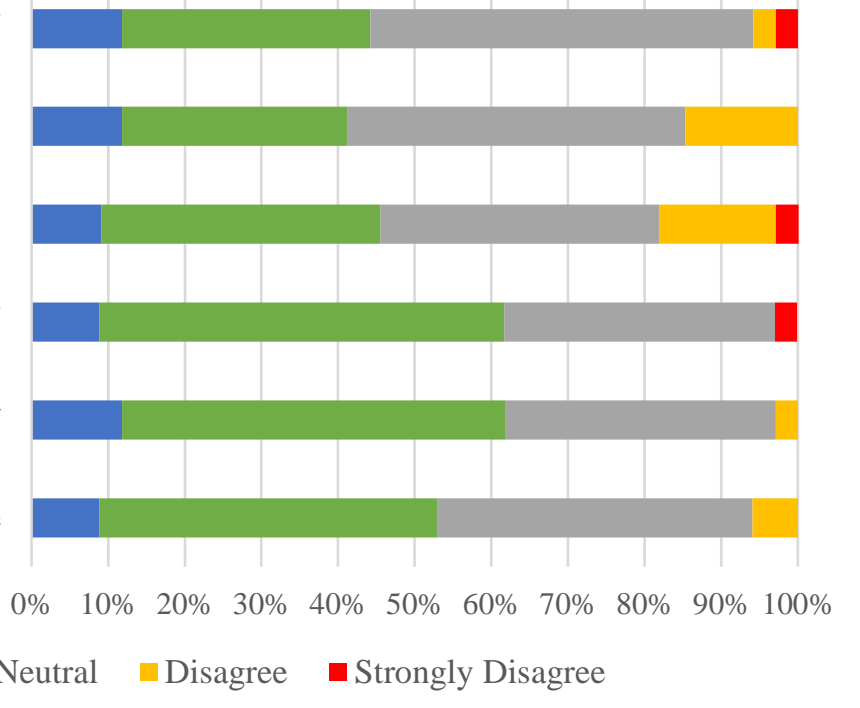

Figure 2. Student perceptions of presentation and organization of the module

Second, we asked students to rate their degree of confidence in their ability to perform several GIS-related tasks before and after using the module. They recorded the strength of their self-efficacy beliefs on a 100-point scale, ranging in 10-unit intervals from 0 ("Cannot do at all"); through intermediate degrees of assurance, 50 ("Moderately certain can do"); to complete assurance, 100 ("Highly certain can do"). A two-way mixed ANOVA was then used to examine whether there was a change in students' self-efficacy scores before (pre) and after using the module 
(post), and whether such change was influenced by the course they had attended. We used an alpha level of 0.05 for all the statistical tests. The results are shown in Table 3.

The results indicate that there was a significant change in the extent to which students felt confident in performing all the GIS-related tasks as listed in the survey before and after using the module $\left(\mathrm{F}(10,39)=20.236, \mathrm{p}=0.000, \eta_{p}{ }^{2}=0.838\right)$, with mean post self-efficacy score for each task significantly higher than pre self-efficacy score. By contrast, there was no significant main effect of course on students' perceptions about their capabilities of performing these GIS-related tasks $\left(\mathrm{F}(10,39)=1.810, \mathrm{p}=0.091, \eta_{p}{ }^{2}=0.317\right)$, with students from the courses in general showing similar degrees of confidence performing these tasks. However, there was a significant interaction between course and pre-post module changes $\left(\mathrm{F}(10,39)=2.425, \mathrm{p}=0.024, \eta_{p}{ }^{2}=0.383\right)$. Specifically, the univariate tests indicate that the changes on students' perceptions of self-efficacy in performing task 4 and task 5 were significantly different between the two courses. As shown in Figure 3 and Figure 4, the degree to which they felt confident in performing these two tasks increased more dramatically for students in the community practice course compared to students in the program evaluation course. Task 4 was "Understand the importance of geographic location and its implication in examining a variety of processes and phenomena in the community" and task 5 was "Use maps to understand the patterns and relationships among several factors, populations, or issues in the community." This difference over two courses specific to these two tasks appears to be reinforced by the course contents. In the first-year community course, students are first introduced to knowledge of the characteristics of communities and appropriate community interventions as well as the analysis of political, cultural, and social forces and their impact on the social environment. By the time students take the program evaluation course, they have already taken the community course and the focus of the second course is much more on program design and program evaluation methods. This is confirmed by the before and after comparison of mean scores of students' self efficacy on performing tasks 4 and 5. As Figures 3 and 4 demonstrate, students in the community course reported lower scores on both task 4 and task 5 than the students in the program evaluation course in their reflection of the time before they took the course. In addition, students in the community course reported greater improvement in both task 4 and task 5 after they took the course. Students in the community course who did not have prior knowledge might have had more engagement with these two tasks throughout the course and therefore had greater improvement in scores for both tasks. 
Table 3. Two-way mixed ANOVA result for student perceptions of self-efficacy in performing GIS-related tasks

\begin{tabular}{|c|c|c|c|c|c|c|}
\hline \multicolumn{7}{|c|}{ Multivariate Test } \\
\hline \multicolumn{2}{|l|}{ Effect } & Value $^{\mathrm{a}} \mathrm{F}$ & Hypothesis df & Error df & Sig. (p) & $\begin{array}{l}\text { Partial Eta } \\
\text { Squared }^{\mathrm{b}}\left(\eta_{p}{ }^{2}\right)\end{array}$ \\
\hline \multicolumn{2}{|l|}{ Course } & 0.683 & 10 & 39 & 0.091 & 0.317 \\
\hline \multicolumn{2}{|c|}{ Pre-post } & 20.236 & 10 & 39 & 0.000 & 0.838 \\
\hline \multicolumn{2}{|c|}{ Pre-post*Course } & 0.617 & 10 & 39 & 0.024 & 0.383 \\
\hline \multicolumn{7}{|c|}{ Univariate Tests } \\
\hline \multicolumn{2}{|c|}{ Effect Measure } & & & $\mathrm{F}$ & Sig. (p) & $\begin{array}{l}\text { Partial Eta } \\
\text { Squared }\left(\eta_{p}{ }^{2}\right)\end{array}$ \\
\hline \multirow[t]{10}{*}{$\begin{array}{l}\text { Pre- } \\
\text { post }\end{array}$} & \multicolumn{3}{|c|}{ Self-efficacy in performing GIS task $1^{\mathrm{c}}$} & 40.559 & 0.000 & 0.458 \\
\hline & \multicolumn{3}{|c|}{ Self-efficacy in performing GIS task 2} & 95.422 & 0.000 & 0.665 \\
\hline & \multicolumn{3}{|c|}{ Self-efficacy in performing GIS task 3} & 95.546 & 0.000 & 0.666 \\
\hline & \multicolumn{3}{|c|}{ Self-efficacy in performing GIS task 4} & 168.361 & 0.000 & 0.778 \\
\hline & \multicolumn{3}{|c|}{ Self-efficacy in performing GIS task 5} & 155.527 & 0.000 & 0.764 \\
\hline & \multicolumn{3}{|c|}{ Self-efficacy in performing GIS task 6} & 81.939 & 0.000 & 0.631 \\
\hline & \multicolumn{3}{|c|}{ Self-efficacy in performing GIS task 7} & 115.831 & 0.000 & 0.707 \\
\hline & \multicolumn{3}{|c|}{ Self-efficacy in performing GIS task 8} & 92.328 & 0.000 & 0.658 \\
\hline & \multicolumn{3}{|c|}{ Self-efficacy in performing GIS task 9} & 112.207 & 0.000 & 0.700 \\
\hline & \multicolumn{3}{|c|}{ Self-efficacy in performing GIS task 10} & 125.463 & 0.000 & 0.723 \\
\hline \multirow[t]{10}{*}{$\begin{array}{l}\text { Pre- } \\
\text { post } * \\
\text { Course }\end{array}$} & \multicolumn{3}{|c|}{ Self-efficacy in performing GIS task 1} & 2.12 & 0.152 & 0.042 \\
\hline & \multicolumn{3}{|c|}{ Self-efficacy in performing GIS task 2} & 0.02 & 0.887 & 0.000 \\
\hline & \multicolumn{3}{|c|}{ Self-efficacy in performing GIS task 3} & 0.714 & 0.402 & 0.015 \\
\hline & \multicolumn{3}{|c|}{ Self-efficacy in performing GIS task 4} & 16.596 & 0.000 & 0.257 \\
\hline & \multicolumn{3}{|c|}{ Self-efficacy in performing GIS task 5} & 11.556 & 0.001 & 0.194 \\
\hline & \multicolumn{3}{|c|}{ Self-efficacy in performing GIS task 6} & 1.008 & 0.320 & 0.021 \\
\hline & \multicolumn{3}{|c|}{ Self-efficacy in performing GIS task 7} & 3.303 & 0.075 & 0.064 \\
\hline & \multicolumn{3}{|c|}{ Self-efficacy in performing GIS task 8} & 1.403 & 0.242 & 0.028 \\
\hline & \multicolumn{3}{|c|}{ Self-efficacy in performing GIS task 9} & 1.081 & 0.304 & 0.022 \\
\hline & \multicolumn{3}{|c|}{ Self-efficacy in performing GIS task 10} & 2.926 & 0.094 & 0.057 \\
\hline
\end{tabular}

a. The statistic is based on Wilks' Lambda test.

b. $\eta_{p}{ }^{2}$ indicates effect size. $\eta_{p}{ }^{2} \geq 0.14$ are large effects; $\eta_{p}{ }^{2} \geq 0.06$ are medium effects; $\eta_{p}{ }^{2} \geq 0.01$ are small effects.

c. GIS task 1: Effectively read and understand maps. GIS task 2: Create a map with all the necessary elements. GIS task 3: Use online mapping tools for collaborating and sharing information. GIS task 4: Understand the importance of geographic location and its implication in examining a variety of processes and phenomena in the community. 
GIS task 5: Use maps to understand the patterns and relationships among several factors, populations, or issues in the community.

GIS task 6: Collect and use secondary data for community assessment and program evaluation.

GIS task 7: Use maps for the analysis and assessment of community needs and assets.

GIS task 8: Use maps as an evidence-based tool in the planning, implementation, and evaluation of community programs and policies.

GIS task 9: Use maps to examine the relationships between social service programs and the target population to identify service gaps or unmet service needs.

GIS task 10: Present the results of needs assessment or evaluation study in a visually appealing format (e.g., map) to inform and educate policy makers, practitioners, and the public.

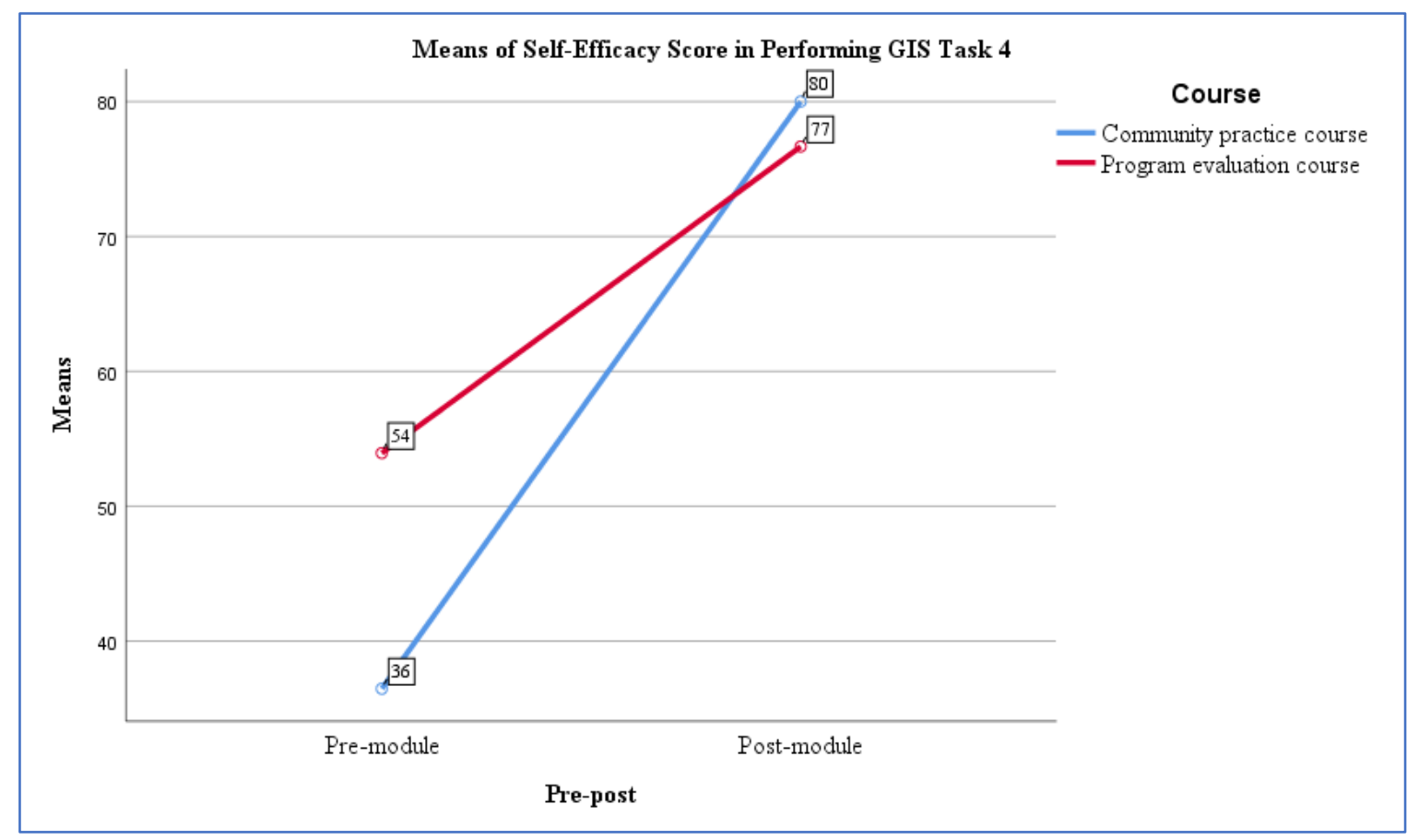

Figure 3. Means of student self-efficacy score in performing GIS task 4 before and after using the module 


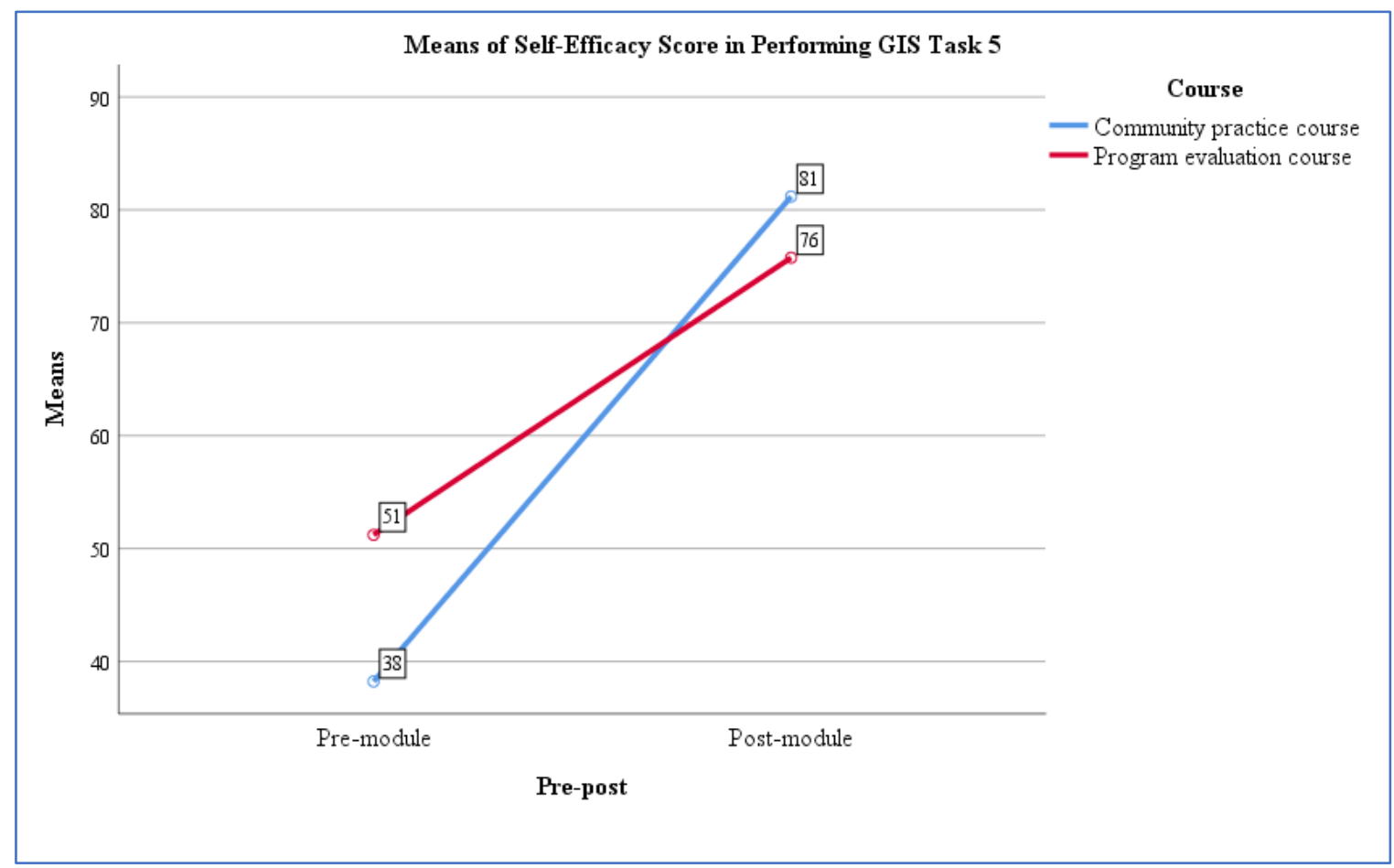

Figure 4. Means of student self-efficacy score in performing GIS task 5 before and after using the module

Third, Figure 5 illustrates the students' responses when asked to what extent the module has contributed to their learning within and beyond the course. In general, students in both courses reported being satisfied with the module and the extent of its usage. Specifically, $100 \%$ of students in the community practice course and $85 \%$ of students in the program evaluation course reported that they felt that the GIS module helped them understand how the course material is relevant beyond the classroom. More than one third of respondents in both courses also agreed that the module has improved their overall understanding of the course material and the module should be implemented into more courses at the university. However, only about one third of students in either course felt that the availability of such a module in a future course would encourage them to enroll in that course. 


\section{Community Practice Course}

The availability of such a module in a future course would encourage me to enroll in that course.

The GIS module should be implemented into more classes at the university.

The GIS module helped me understand how the course material is relevant beyond classroom.

The GIS module improved my overall understanding of the course material.

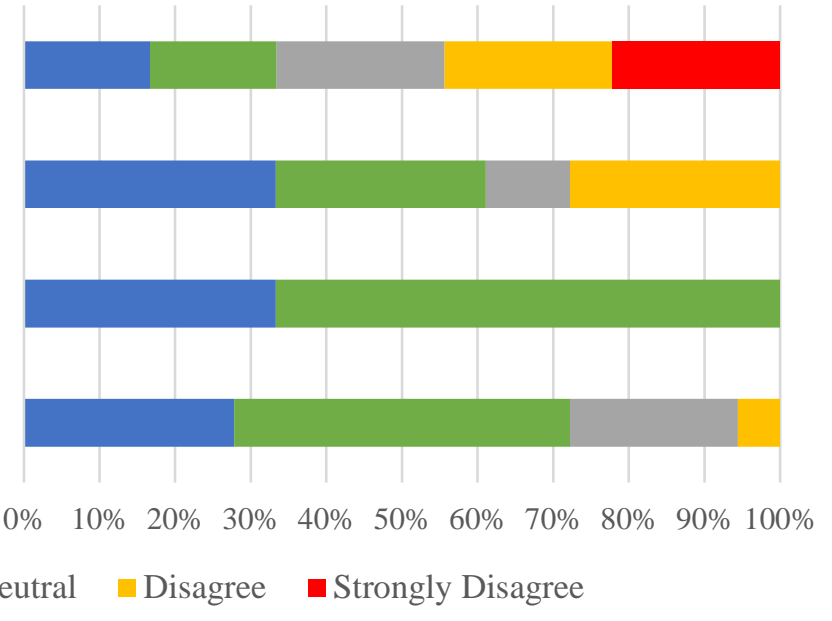

$$
\square \text { Strongly Agree } \square \text { Agree } \quad \text { Neutral } \square \text { Disagree } \square \text { Strongly Disagree }
$$

\section{Program Evaluation Course}

The availability of such a module in a future course would encourage me to enroll in that course.

The GIS module should be implemented into more classes at the university.

The GIS module helped me understand how the course material is relevant beyond classroom.

The GIS module improved my overall understanding of the course material.

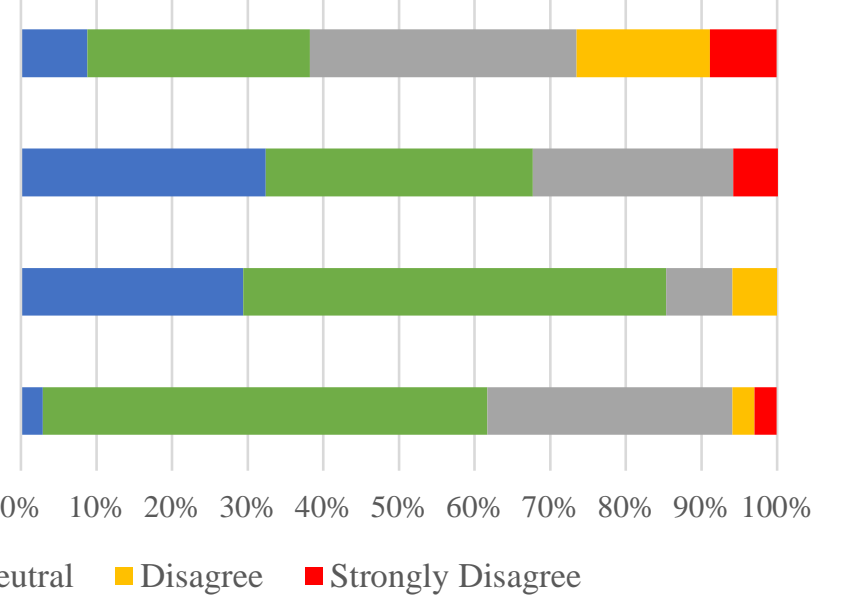

Figure 5. Student perceptions of how the module contributed to their learning within and beyond the course

In addition, we asked to what extend the students felt the module has contributed to their future service-learning activities. According to the independent t-test result, there was no significant effect for course in terms of the average scores of students' perception on the module's contribution to their service learning, $\mathrm{t}(50)=-1.09, \mathrm{p}=0.28$. Figure 6 indicates that students in both courses overwhelmingly (i.e., ranging from $85 \%$ to $100 \%$ ) perceived that the module has better prepared them for their future service-learning activities related to seven out of eight items, especially in the following aspects. More than $90 \%$ of the respondents agreed that the module has at least somewhat helped them to have an objective and comprehensive view of the community, to understand the community's strengths and the challenges it faces, as well as to transform what they have learned from the classroom to their work in the community. However, there was one exception. The item, "have a competitive advantage when seeking employment" still gained over 
$72 \%$ of students' agreement but not by as overwhelmingly high a percentage as the other seven items, with the remaining $28 \%$ of students reported that they did not feel so. This result may indicate that GIS has not been embraced as part of social work practice skill sets. Wilson (2016) pointed out despite the usefulness of GIS, the usage and application of GIS in the social work profession is still uncommon. This result might also be attributed to the individual respondents' future career preference. Some students have more career interest in macro practice, while others prefer micro, clinical practice for their future career. According to Felke (2014), over four course offerings, students who reported that they did not feel they would use GIS in the future were most likely to be the ones having clinical practice as their future career choice. Since we did not ask their future career choice, there was no way of testing this effect in our study.

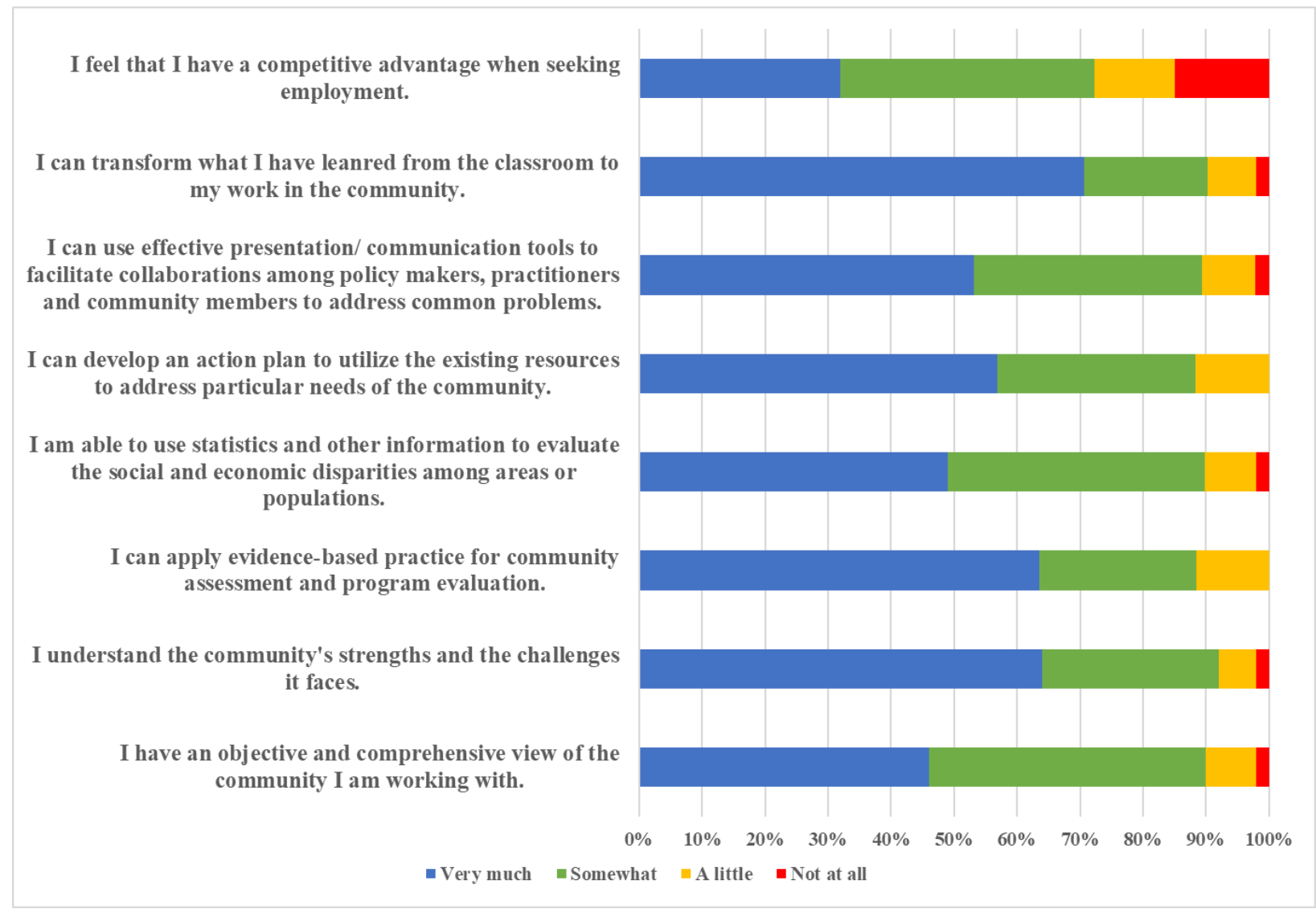

Figure 6. Student perceptions of how the module contributed to their future service-learning activities

\section{DISCUSSION}

The online module was integrated into the targeted courses by blending it with course materials and in-class activities. By doing so, this project facilitated the implementation of innovative teaching methods, such as blended learning, into social work classrooms. Student survey findings indicate that students found significant value in using the GIS online module and its contribution to their own learning and future application. Since it is accessible to students anywhere and at any 
time, this online module allowed for student-centered, active learning in a comfortable environment with minimal pressure or time constraints, which has been found to improve both student learning experience and academic achievement (Mui, Nelson, Huang, He, \& Wilson, 2015). It also offers course instructors the flexibility to utilize the module in the best way they see fit. They can integrate this module along with lectures and class discussions into a course assignment or assessment test, or they can use it in a more passive sense, such as assigned course reading. Moreover, the learning module can also be used for training existing faculty and staff members who are interested in learning GIS and asset mapping for research or teaching purposes.

Previous studies have demonstrated that community asset mapping with the use of GIS can help to engage students in working directly with community members, thus promoting community awareness and engagement among students (Garoutte \& McCarthy-Gilmore, 2014; Graham, Carlton, Gaede, \& Jamison, 2011). Furthermore, students can then develop an action plan to utilize the existing resources highlighted by the asset maps to address particular needs of a community. This would prepare them to transform what they have learned through the module into future community work. Additionally, the module can serve as a starting point for students to develop greater capacities in digital mapping, data collection, and management - a competitive skill set for macro practice. More importantly, digital community asset maps can be easily shared with the community, which enables students to produce information that is more accessible and comprehensible for the residents. The community can then use the information to make evidencebased decisions for its program evaluation and planning (Graham et al., 2011). This sharing of ideas through maps can help to strengthen the partnership between the university and the community, which is in line with best practices for service learning.

Although this module is primarily designed for the integration of GIS and community asset mapping into class content within the field of social work, it can be extended to courses in other areas, such as sociology, criminal justice, language study, education, etc. Some components of this module can be used to teach concepts related to communities, as well as the relationship between individuals and social systems, in order to connect students with service-learning experiences. In this way, this project can potentially facilitate communications across courses in different disciplines, thus making it an attractive and multi-disciplinary investment that benefits the entire university community.

This project involved collaborative efforts between many campus stakeholders, including library staff, faculty members, library and faculty administrators, and pedagogical staff from the Office of Open Learning. The module was developed within Leddy Library, with input and assistance solicited from faculty members, graduate students, instructional designers, and elearning specialists throughout the module's development. In doing so, the project fostered campus-wide discussions and collaborations on curriculum design and pedagogical approaches, thereby providing insight for future directions in teaching and learning at the university.

\section{ACKNOWLEDGEMENT}

This project was funded by the University of Windsor Centred on Learning Innovation Fund (CLIF) program. Authors would like to acknowledge the valuable contribution of two research assistants to this project: Dwayne Barris ( $\mathrm{PhD}$ student in the School of Social Work, University of Windsor) and Julia Zheng (PhD student in the Department of Computer Science and Engineering, Michigan State University). 


\section{References}

Bauer, T., Kniffin, L. E., \& Priest, K. L. (2015). The future of service-learning and community engagement: asset-based approaches and student learning in first-year courses. Michigan Journal of Community Service Learning, 22(1), 89-93.

Centre for Community Health and Development. (2020). Identifying Community Assets and Resources. Community Tool Box, Center for Community Health and Development, the University of Kansas. Retrieved from https://ctb.ku.edu/en/table-of-contents/assessment/assessing-communityneeds-and-resources/identify-community-assets/main

Donaldson, L. P., \& Daughtery, L. (2011). Introducing asset-based models of social justice into service learning: A social work approach. Journal of Community Practice, 19(1), 80-99.

Felke, Thomas, P. (2019). The use of Geographic Information Systems for social work education, research, and practice. In L. Goldkind, L. Wolf, P.P. Freddolino (Eds.), Digital social work: Tools for practice with individuals, organizations, and communities. (pp. 145-167). New York, NY: Oxford University Press.

Felke, Thomas, P. (2014). Building capacity for the use of Geographic Information Systems (GIS) in social work planning, practice, and research. Journal of Technology in Human Services, 32(1-2), 81-92.

Garoutte, L. \& McCarthy-Gilmore, K. (2014) Preparing students for community-based learning using an asset-based approach. Journal of the Scholarship of Teaching and Learning, 14(5), 48-61.

Gerstenblatt, P. \& Gilbert, D.J. (2014) Framing service learning in social work: an interdisciplinary elective course embedded within a university-community partnership. Social Work Education, 33, 1037-1053.

Graham, S. R., Carlton, C., Gaede, D., \& Jamison, B. (2011). The benefits of using geographic information systems as a community assessment tool. Public Health Reports (Washington, D.C.: 1974), 126(2), 298-303.

Harkavy, I. (2004) Service-learning and the development of democratic universities, democratic schools, and democratic good societies in the 21 st century. In M. Welch \& S. H. Billig (Eds.), New perspectives in service-learning: Research to advance the field (pp. 3-22). Greenwich, CT: Information Age Publishing.

Hillier, A. E. (2007). Why social work needs mapping. Retrieved from http://repository.upenn.edu/spp_papers/86

Jacoby, B. A. (Ed.). (2009). Civic engagement in higher education. San Francisco, CA: Jossey-Bass.

Kretzmann, John P. \& John L. McKnight. (1993). Building communities from the inside out: A path towards finding and mobilizing a community's assets. ACTA Publications, Chicago, IL.

Lemieux, C. M., \& Allen, P. D. (2007). Service learning in social work education: The state of knowledge, pedagogical practicalities, and practice conundrums. Journal of Social Work Education, 43(2), 309-326.

Maclachlan, J., Brodeur, J. J., Bagg, J. L., Chiappetta-Swanson, C., Vine, M. M., \& Vajoczki, S. (2014). An assessment of a blended learning model for information and geospatial literacy. Toronto: Higher Education Quality Council of Ontario.

McGuire, L. E., \& Majewski, V. (2011). Editorial: Social work and service learning in the age of competency-based education. Advances in Social Work, 12(1), 1-vii.

Mui, A. B., Nelson, S., Huang, B., He, Y., \& Wilson, K. (2015). Development of a web-enabled learning platform for geospatial laboratories: Improving the undergraduate learning experience. Journal of Geography in Higher Education, 39(3), 356-368.

Phillips, A. (2011). Service-learning and social work competency-based education: A 'goodness of fit'? Advances in Social Work, 12(1), 1-20.

Sharpe, P.A., Greaney, M. L., Lee, P., \& Royce, S.W. (2000). Assets-oriented community assessment. Public Health Reports (Washington, D.C.: 1974), 115(2/3), 205-211. 
Taylor, A., Butterwick, S., Raykov, M., Glick, S., Peikazadki, N. \& Mehrabi, S. (2015). Community service learning in Canadian higher education. Knowledge Synthesis Report for the Social Sciences and Humanities Research Council.

Lamb, Theodore. (2005). The retrospective pretest: an imperfect but useful tool. Harvard Family Research Project: The Evaluation Exchange, XI(2). Retrieved from https://archive.globalfrp.org/evaluation/the-evaluation-exchange/issue-archive/evaluationmethodology/the-retrospective-pretest-an-imperfect-but-useful-tool

University of Windsor. (2010). The Strategic Plan for the University of Windsor. Retrieved from http://www1.uwindsor.ca/hr/strategic-plan

Wier, K. R., \& Robertson, J. G. (1998). Teaching geographic information systems for social work applications. Journal of Social Work Education, 34(1), 81-96.

Wilson, K.O. (2016). Beyond the ecomap: GIS as a promising yet chronically underutilized method in social work. Social Work and Social Sciences Review, 18(2), 58-66.

\begin{abstract}
About the authors
Xue (Carina) Luo holds a BCs and an MSc in Geomatics from the University of Waterloo, Ontario, Canada. Now Carina is a Geospatial Data Analyst at Leddy Library, University of Windsor, Ontario, Canada. She is responsible for the provision of expertise in developing and delivering geospatial data services and programs offered to members of the University of Windsor community. Carina's research interests are in the field of GIS and data analysis with diverse application areas in crime and public health, food environments, and higher education.

Wansoo Park, PhD, MSW, is Associate Professor and PhD Coordinator, School of Social Work, at University of Windsor, Ontario, Canada. She teaches program evaluation and community practice courses at the graduate level. Her research interest includes community based participatory research methods, health equity, health care access, and international social work education.
\end{abstract}

